\title{
Energy, economic, and environmental assessment of the integrated production of palm oil biodiesel and sugarcane ethanol
}

doi: https://doi.org/10.1016/j.jclepro.2021.127638

url: https://www.sciencedirect.com/science/article/abs/pii/S0959652621018564

\section{Authors}

Eric Alberto Ocampo Batlle, José Carlos Escobar Palacio, Electo Eduardo Silva Lora, Edson Da Costa Bortoni, Luiz Augusto Horta Nogueira, Gaylord Enrique Carrillo Caballero, Alisson Aparecido Vitoriano Julio, Yulineth Cárdenas Escorcia

\section{Abstract}

The key objective of this study was to evaluate and compare, within the concept of integrated biorefining, the potential environmental gains of the life cycle, economic feasibility and energy balance of the production of bioenergetics from palm and sugarcane. In this context, the research model developed in this work involved several assessment techniques; in terms of environmental assessment, the tool used was the Life Cycle Assessment (LCA) from the Well-To-Tank perspective, which is based on the LCA "cradle-to-gate" assignment method. The environmental assessment was performed using SimaPro v.8.0.3 software and the impacts were quantified using the IMPACT $2002+$ method. On the other hand, energy performance evaluation was based on the 1st law indicators. Likewise, economic feasibility was based on the evaluation of the fixed capital investment index and the estimate of investment costs for the entire integrated system. Two different scenarios were proposed in order to compare and evaluate traditional systems with the integrated biorefinery. The first conversion scenario (baseline scenario) consisted of a traditional palm oil extraction plant in addition to an ethanol and sugar plant, concerning the use of fossil fuels in all stages of production. The second conversion scenario (improved scenario) explored the substitution of fossil energy sources as well as the energy recovery of residual biomass in more efficient energy conversion systems. The results indicated significant reductions of $29.5 \%$ and $29.1 \%$ in the global warming impact category when the baseline scenario was compared to the improved scenario. Additionally, the improved scenario achieved a reduction of $2.1 \mathrm{~g}$ CO2eq MJ-1 (ethanol) and $2.61 \mathrm{~g} \mathrm{CO2eq} \mathrm{MJ-1} \mathrm{(biodiesel).} \mathrm{On} \mathrm{the} \mathrm{other} \mathrm{hand,} \mathrm{the} \mathrm{improved} \mathrm{scenario} \mathrm{presented}$ better energy rates since it showed an increase of $3.82 \%$ in the global efficiency of the system and produced $106.32 \mathrm{kWh}$ more per ton of processed raw material. Finally, when considering the Life Cycle Energy Efficiency, an increase of $83 \%$ was observed and in the case of the Renewability Factor showed an increase of 7.12 energy units. Integration is also economically feasible; however, it could be significantly improved through fiscal incentives founded on the reduction of fossil energy use, enhanced conversion yielding, and improvements in conversion technologies.

\section{Keywords}

Integrated biofuel production, Biorefinery, Energy performance, Sustainability, Environmental impacts 